\title{
STEAM e design thinking: ferramentas transdisciplinares no ensino de inglês
}

\author{
Liana Borges de Resende Rocha* \\ Ana Letícia Souza Garcia**
}

Resumo

O presente artigo tem a finalidade de refletir sobre como a aplicação do conceito STEAM (Science, Technology, Engineering, Arts and Maths) e do design thinking na sala de aula pode contribuir para um ensino de língua inglesa transdisciplinar. Incorporando, de forma transdisciplinar, os saberes da Ciências, Tecnologia, Engenharia, Artes e Matemática, o STEAM é uma proposta de ensino globalizadora, baseada em projetos, que relaciona os conteúdos disciplinares, a partir de problemas reais, para que, integrados à estrutura de conhecimento do indivíduo, assumam significado em uma situação concreta. A implementação de atividades em sala de aula utilizando a abordagem STEAM é um desafio para professores de línguas, uma vez que se inspira na metodologia do design thinking e é baseado em cinco formas interconectadas de conhecimento: autoconhecimento cultural, conhecimento relacional, conhecimento crítico, conhecimento visionário e ético, e conhecimento em ação. Ao final das aulas, pôde-se perceber que os alunos enriqueceram seus conhecimentos não só específicos da disciplina de língua inglesa, mas em diversas outras áreas, como história, arte, design e geografia.

Palavras-chave: ensino de inglês, transdisciplinaridade, design thinking, STEAM.

\section{STEAM and design thinking: transdisciplinary tools in teaching English}

\section{Abstract}

This paper aims to reflect how the concept of STEAM (Science, Technology, Engineering, Arts and Maths) and design thinking can provide transdisciplinary in English teaching classes. Integrating, on a transdisciplinary way, knowledges related to Science, Technology, Engineering, Arts and Maths, the STEAM is a globalized proposal of teaching in order to relate different subjects to solve a real problem, so that the person may act significantly in a concrete situation. The implementation of activities in the classroom using the STEAM approach is a challenge to English teachers, once they have to be inspired by the design thinking methodology based on five interconnected ways of knowledge: cultural self-knowledge, relational, critical, visionary and ethical, and action. At the end of the classes, we could notice that the students enriched their knowledge not only specific to the English language subject, but in several other areas such as history, art, design and geography.

Keywords: english teaching, transdisciplinarity, design thinking, STEAM.

\section{Introdução}

A Linguística Aplicada ao ensino de línguas tem passado por diversas mudanças epistemológicas, devido ao momento de grande ebulição sociocultural e político-histórica

\footnotetext{
* Mestra em Artes em Empreendedorismo para a Prática Criativa pelo Plymouth College of Art no Reino Unido e Bacharel em Design de Interiores pela Pontifícia Universidade Católica de Goiás (PUC/GO). Email: lianaresende@gmail.com.

*** Mestra em Letras e Linguística (UFG) e Graduada em Letras Português/Inglês (UFG). Professora no IFG (Câmpus Senador Canedo). E-mail: analeticiasg@gmail.com.
} 
que estamos vivenciando, caracterizado por desenvolvimentos tecnológicos que têm afetado o modo como vivemos e pensamos. Período esse em que concepções modernas têm sido questionadas, problematizadas e redefinidas, principalmente em relação a formas de produção de conhecimento. Assim, autores como Moita Lopes (2006) têm defendido uma Linguística Aplicada (in)disciplinar que teorize e dialogue com o mundo contemporâneo e com as práticas sociais dos sujeitos.

Ao analisar a multiplicidade de fenômenos que frequentemente são agrupados e chamados, de maneira generalizante, de globalização, Fabrício (2006) ressalta as seguintes características do momento contemporâneo: a) transnacionalização das dimensões política e econômica; b) compressão espaço-tempo possibilitada pela velocidade da circulação de discursos e imagens disponibilizadas em tempo real pela TV ou pela internet; c) mestiçagem de discursos e práticas tradicionalmente pertinentes a domínios discretos; d) novos roteiros de subjetivação decorrentes da estruturação das relações sociais como consumo; e) desvalorização de compromissos comunais e a consequente privatização das ações na busca de soluções individuais para problemas produzidos socioculturalmente e; f) crescente domínio e despolitização do espaço público, decorrente do esvaziamento do sentido moral dessa arena. Por conseguinte, Fabrício (2006, p. 47) afirma que:

[...] está em operação um campo de forças plurais que entrelaça uma série de novos significados, modos de produção de sentido, práticas, técnicas, instituições, procedimentos de subjetivação e relações discursivas, tornando problemática a adoção de pontos de vista e explicações causais simplistas a respeito dos fenômenos sociais.

A autora ainda acrescenta que a Linguística Aplicada está em processo de reconstrução, reinventando-se de forma a não investir na delimitação de um perfil disciplinar claramente contornado, mas passa a apostar no diálogo transfronteiras envolvendo diversas áreas e diferentes modos de produção de conhecimento, e a assimilar a metáfora da trama como modo de conhecer - compreendendo que o conhecimento produzido e as "verdades" a ele atribuídas são construídos pela sociedade (FABRÍCIO, 2006). Essas teorizações a respeito do aspecto transdisciplinar da Linguística Aplicada nos motivaram a responder a seguinte pergunta neste estudo: como a aplicação do conceito STEAM (Science, Technology, Engineering, Arts and Maths) e do design thinking na sala de aula pode contribuir para um ensino de língua inglesa transdisciplinar? 
Assim, o presente artigo foi dividido em cinco partes, consistindo dessa introdução; na seção seguinte, do esclarecimento sobre o papel do design thinking no contexto escolar; depois, da explicação do motivo da abordagem STEM ter sido transformada em STEAM; posteriormente, da apresentação de como o conceito STEAM foi colocado em prática em três aulas de língua inglesa em um contexto de educação bilíngue de elite e, por último, das considerações finais.

\section{O papel do design thinking no contexto escolar}

A humanidade tem uma longa história com o design, como pode ser evidenciado através dos artefatos criados por civilizações antigas, nas tradições continuadas de design vernacular e no tradicional artesanato. Tudo que nos rodeia foi projetado de alguma forma. Se não é um elemento da natureza, possivelmente foi projetado e a qualidade do design deste produto reflete diretamente na nossa qualidade de vida. A habilidade de os designers projetarem produtos eficazes, eficientes, criativos e estimulantes é importante para todos nós (CROSS, 2011). Cross (2011, p. 3), ao conceituar design thinking, esclarece que

\footnotetext{
qualquer um pode - e faz - design. Nós todos projetamos quando planejamos que alguma coisa nova aconteça, mesmo que ela possa ser somente a nova versão de uma receita, uma mudança nos móveis da sala de estar ou o layout de um website. A evidência oriunda das diferentes culturas do mundo todo e os designs criados pelas crianças e adultos sugerem que todos somos capazes de projetar. Então design thinking é algo inerente à cognição humana, é parte essencial do que nos faz humanos.
}

Segundo o autor, o design thinking é um processo interativo onde procuramos entender o usuário, fazer suposições e redefinir os problemas numa tentativa de identificar estratégias alternativas e soluções que possam não estar aparentemente visíveis em nosso nível inicial de entendimento. Ao mesmo tempo, o design thinking proporciona uma abordagem baseada na solução de problemas. É um processo que nos ajuda a levantar questionamentos, fazer suposições e problematizar suas implicações. Também envolve experimentação: desenhos, protótipos e tentativas de criação de conceitos e ideias. Esse processo de metodologia aplicado à solução de problemas encoraja um novo modelo mental que permite que os envolvidos vejam um mundo cheio de possibilidades, onde a 
criatividade de cada indivíduo, junto com o processo de inovação, permite resolver os problemas mais improváveis, sendo eles do mundo real, relacionados às particularidades de cada indivíduo, incentivando-se, assim, o pensar globalmente e o agir localmente (BACIC; MORAN, 2018).

O design thinking envolve a solução ativa de problemas por meio do engajamento e mudança do mundo em que vivemos (GOLDMAN; KABAYDONDO, 2017). Goldman e Kabaydondo (2017) baseiam-se nas teorizações vygotskyanas para afirmar que o design thinking tem como fundamento principal o trabalho em equipe e profundas colaborações entre os indivíduos envolvidos no processo e essas oportunidades de interações são consideradas essenciais para o processo de aprendizagem. Já Papert e Harrel (1991, citados por GOLDMAN; KABAYDONDO, 2017) afirmam que, assim como o construtivismo, o design thinking proporciona aprendizado por meio do contato com materiais, objetos e experiências das quais o aprendiz reflete e constrói conhecimento.

Por conseguinte, aprender por meio do design thinking é complexo e transformador, uma vez que as promessas e possibilidades associadas a essa teoria podem ser cativantes para os educadores. A partir das teorizações a respeito do design thinking, estudantes podem interagir e desenvolver entendimento em uma determinada área (inglês, matemática, arte etc.) ou desenvolver habilidades de empatia com os pares, colaborando ou construindo protótipos (GOLDMAN; KABAYDONDO, 2017). Henriksen (2017) ressalta que o design, ou o design thinking, promove ainda uma metodologia a ser seguida, capaz de dar suporte e expandir a visão do modelo STEAM (Science, Technology, Engineering, Arts and Mathematics). O design thinking fornece a estrutura para que os professores possam desenvolver práticas mais criativas e transdisciplinares - como uma estrutura capaz de guiar o pensamento, que faça parte das experiências vivenciadas pelos estudantes através do STEAM aplicado na sala de aula.

\section{Do STEM ao STEAM}

Segundo Spector et al. (2015), a história da educação vem sendo gradativamente construída ao longo dos anos. E, apesar das várias mudanças ocorridas no desenrolar de sua história, ainda mantém como objetivo básico o treinamento das pessoas com a finalidade de que elas sejam bem-sucedidas na vida. Esse treinamento deve envolver a 
procura por habilidades e conhecimentos que, no mundo pós-moderno, está associado com o desenvolvimento do pensamento crítico e a resolução de problemas, e acima de tudo, deve manter o propósito de desenvolver cidadãos responsáveis e indivíduos que se disponham a aprender durante a vida toda.

Fisher e Scriven (1997, citados por SPECTOR et al., 2015) esclarecem que foi a partir dessa visão que os objetivos educacionais mais amplos puderam ser repensados e desconstruídos em subsegmentos que podem ser aprendidos e apoiados através de instruções e suporte de desempenho. Além disso, podem futuramente ser categorizados em termos de domínio de uma tarefa específica ou um grupo de conhecimentos relativos e habilidades que podem se tornar parte de um currículo. Por exemplo, a categoria pensamento crítico pode ser decomposta em diversas subcategorias como: análise de argumentos, identificação de hipóteses, avaliação de evidências, formulação de implicações, dentre outras. Em cada nível de decomposição, em muitos casos, é possível se especificar medidas e formas de avaliação que podem ser associadas à competência ou performance de excelência. Essa linha de pensamento de objetivo final para grupo de objetivos, associada às metodologias de avaliação, é a base do currículo fundamentado em competências que se encontra implementado em muitas grades curriculares. Esse pensamento vem sendo utilizado para estruturar os currículos educacionais primários, secundários e até mesmo terciários, em várias áreas de ensino.

Para Portnoi et al. (2010), a necessidade de aumentar a capacidade de criar e sustentar economias globalmente competitivas culminou no crescimento dos currículos baseados em competências. A pressão para se criar uma força-tarefa educacional competitiva no século XXI ocasionou a ênfase do modelo STEM (Science, Technology, Engineering and Mathematics). Enquanto as Novas Tecnologias de Informação e Comunicação (NTIC) tornam possível projetar, desenvolver e implantar poderosos ambientes de aprendizado STEM, muitas dessas tecnologias podem também dar suporte à aprendizagem que não está estritamente ligada ao desenvolvimento de competências.

Ferral (2011) ressalta que esse modelo baseado em competências não foi facilmente adaptado nas artes liberais e humanidades. Em muitas áreas das artes liberais a ênfase está na criatividade e nas expressões pessoais que não são facilmente medidas ou avaliadas. Existem evidências que comprovam que a educação de artes liberais, com a rica infusão das humanidades, pode preparar um indivíduo para ser bem-sucedido em 
diversas ocupações que requerem criatividade e pensamento crítico. É nesse contexto que as artes e as humanidades são agregadas ao modelo STEM, onde é acrescentada a letra A se tornando STEAM. Assim, STEAM é o movimento iniciado pela Rhode Island School of Design para integrar arte e humanidades ao currículo STEM. A educação STEAM propõe o engajamento dos estudantes num aprendizado transformativo, que é baseado em cinco formas interconectadas de conhecimento: autoconhecimento cultural, conhecimento relacional, conhecimento crítico, conhecimento visionário e ético, e conhecimento em ação (SPECTOR et al., 2015).

O modelo STEAM tem ganhado força nas escolas dos Estados Unidos desde que o presidente, à época, Barack Obama solicitou aos educadores, em 2011, que priorizassem o aprendizado das habilidades do século XXI. Com milhões em financiamento para treinamento de professores, subsídios, pesquisa e mensurabilidade, o STEAM se tornou um nome familiar na prática educacional estadunidense (GUN, 2017).

\section{A aplicação do STEAM no ensino da língua inglesa}

Segundo Fabrício (2006), há uma tendência atualmente nos estudos da Linguística Aplicada em focalizar a linguagem como prática social e observá-la em uso, levando-se em consideração o contexto local e global no momento contemporâneo. Dessa forma, é importante ressaltar que o presente estudo foi realizado em uma escola de educação bilíngue de elite (Português/Inglês), localizada em uma área nobre da cidade de Goiânia, no Centro-Oeste do Brasil. Nessa instituição, estudam aproximadamente 600 crianças desde a Educação Infantil até o Ensino Fundamental 2. Na Educação Infantil, a língua inglesa é utilizada na maior parte do tempo e as crianças são incentivadas a brincar, a cantar músicas e a ouvir histórias em inglês. No Ensino Fundamental 1, os conteúdos de Língua Portuguesa, Matemática, História e Geografia são ministrados em português e os conteúdos de Língua Inglesa, de Ciências, assim como os das aulas extracurriculares, são ministrados em inglês. No Ensino Fundamental 2, a primeira aula, todos os dias, é a de inglês e as demais disciplinas são ministradas em português.

É importante ressaltar que o principal objetivo da educação bilíngue de elite é adicionar uma segunda língua, diferente da que é falada em casa, encaixando-se na tipologia IV da classificação de Cummins (MELLO, 2010). Nessa classificação, os 
programas do Tipo I são destinados às populações indígenas; os do Tipo II são os que se destinam à manutenção e revitalização de uma língua minoritária nacional; os do Tipo III relacionam-se às línguas minoritárias internacionais; e os do Tipo IV, ao grupo linguístico majoritário. No entanto, esses conceitos não são estáticos. A escola em que esse estudo foi realizado é classificada como Tipo IV, por ser um modelo destinado às populações que falam a língua majoritária nacional e que objetivam à adição de uma segunda língua de prestígio internacional (no caso, a língua inglesa); porém, em determinadas situações, encaixa-se no Tipo III, pois recebe alunos de outros países que não falam a língua nacional e, nesses casos, a língua inglesa é o meio para que eles se comuniquem e aprendam componentes curriculares na língua portuguesa. Teorizações mais recentes em educação bilíngue levam em consideração essa classificação monoglóssica mais tradicional de Cummins (MELLO, 2010), mas García (2009) afirma que tal classificação nem sempre faz sentido e, por isso, acrescenta mais dois tipos numa perspectiva heteroglóssica: o modelo dinâmico recorrente (recursive dynamic model) e o modelo dinâmico (dynamic model). A autora define que o modelo dinâmico recorrente tem o objetivo de revitalizar práticas linguísticas que estão quase silenciadas, enquanto o modelo dinâmico compreende que a criança apresenta diversos graus de bilinguismo, de acordo com o contexto em que está inserida (se a família fala diferentes línguas, se ela viveu em vários países etc.), e aceita suas práticas linguísticas múltiplas, não lineares e complexas.

Dessa forma, a partir das teorizações explicitadas até aqui, foi elaborado um plano de aula considerando a abordagem STEAM e o design thinking com a finalidade de refletirmos sobre os benefícios na aprendizagem dos alunos de um agrupamento de nível A2 (segundo o CERF) de inglês, todos pertencentes ao Ensino Fundamental 2, no contexto de uma escola de educação bilíngue de elite em Goiânia. Nesse segmento, os alunos do $6^{\circ}$ ao $9^{\circ}$ ano fazem, no início do ano letivo, um teste de nível e são agrupados de acordo com os resultados que atingiram, levando-se em consideração o CERF. O plano de aula foi dividido em uma sequência didática composta por 3 aulas, embasadas no livro literário Michelangelo (Figura 1), publicado pela editora Children's Press em 2014, como parte da coleção Getting to know the world's greatest artists (Conhecendo os melhores artistas do mundo). O livro conta a história de Michelangelo de forma lúdica e ilustrada. 
Figura 1 - Capa do livro Michelangelo

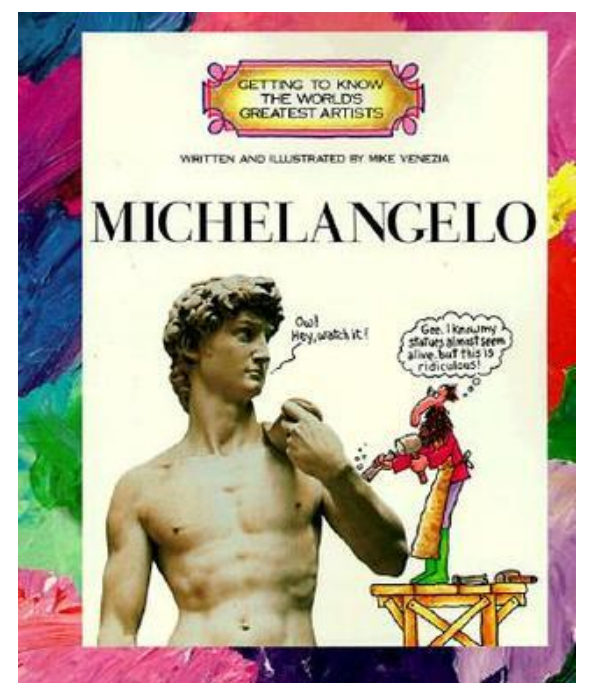

Fonte: website Amazon.com ${ }^{1}$.

Na primeira aula, a professora contextualizou a arte e o período do renascimento, utilizando a língua inglesa para explicitar o assunto. Foram apresentadas as características desse movimento artístico que se iniciou no século XIV, e os alunos puderam conhecer os artistas e obras mais relevantes do período. Na segunda aula, também, utilizando-se de repertórios linguísticos do inglês, foram apresentados alguns trabalhos de pintura e escultura de Michelangelo, e foi feita uma análise de algumas de suas obras. Cada aluno pôde expor o que sentia ao estar diante da obra, e foram discutidas também as possíveis intenções do artista ao pintar/esculpir aquelas obras.

$\mathrm{Na}$ terceira aula, o foco foi na pintura de teto da Capela Sistina (Vaticano, Itália) realizada por Michelangelo entre os anos de 1508 e 1512. Foi realizado um tour virtual com os alunos por meio de um vídeo do YouTube, e a professora explicou as condições pelas quais a pintura foi realizada e quais as consequências, inclusive de saúde, que o artista sofreu para terminar a obra. Após discussão, a professora projetou parte da obra chamada "A criação de Adão", e os alunos foram encorajados a se deitarem embaixo de suas carteiras, onde havia papéis em branco fixados, para que pudessem elaborar uma releitura da obra em condições parecidas com a de Michelangelo.

\footnotetext{
${ }^{1}$ Disponívelem: https://www.amazon.com/Michelangelo-Getting-Worlds-Greatest-Artists/dp/0516422936. Acessoem: 12 nov. 2020.
} 
Figura 2 - Detalhe teto da Capela Sistina

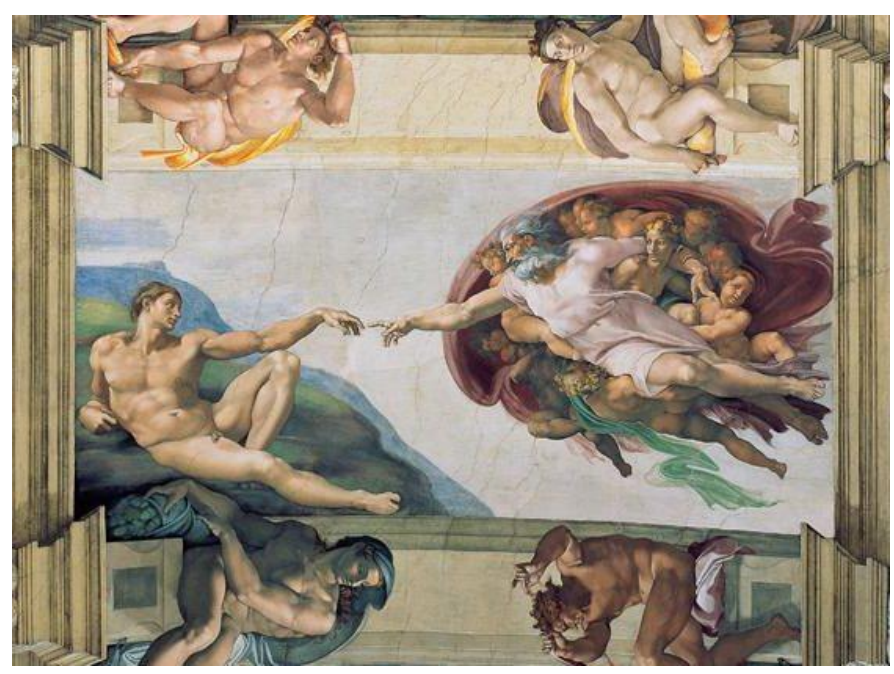

Fonte: website History.com ${ }^{2}$.

Durante o período em que estiveram desenhando, os alunos conseguiram perceber as dificuldades que o artista enfrentou, na época, ao realizar a obra. Após o término do exercício, a professora problematizou os desafios enfrentados por Michelangelo e, baseados na abordagem STEAM, eles foram encorajados a encontrar soluções para as dificuldades vivenciadas por Michelangelo ao elaborar uma pintura grandiosa no teto de uma igreja na Itália. Como os alunos tiveram a oportunidade de experenciar os obstáculos possíveis enfrentados pelo artista, foram capazes de elaborar diversas soluções plausíveis, dentre elas, o uso de moldes para que a pintura fosse realizada com mais rapidez, bem como uma maneira de realizar essa pintura em um tipo de material que posteriormente pudesse ser transferida para o teto, permitindo que o artista pudesse fazer a pintura em plano vertical de forma mais confortável.

\section{Considerações Finais}

A preocupação dos professores de língua inglesa não deve ser a de ensinar somente a língua como estrutura, mas precisa ser a busca por uma vida melhor por meio da língua para possibilitar a construção de conhecimentos que vão além da disciplina de inglês. Concordamos com Fabrício (2006, p. 62) quando ela conclui que

\footnotetext{
2 Disponível em: https://www.history.com/news/7-things-you-may-not-know-about-the-sistine-chapel.
} Acesso em: 12 nov. 2020. 
não devemos ver a multiplicidade de construtos presentes em uma Linguística Aplicada híbrida e inter/transdisciplinar com temor pelo risco da perda das especificidades da área ou de sua essência. Aprendemos na cultura a olhar com desconfiança para as misturas, os cruzamentos, as metamorfoses e a diversidade; em razão disso, a pluralidade de referências costuma nos desconcertar. "Desaprender" a noção de negatividade atribuída à mestiçagem e apostar na fluidez e nos entre-espaços como um modo privilegiado de construção de conhecimento sobre a vida contemporânea é, assim, um grande desafio.

Esse desafio de apostar na fluidez como construção de conhecimento foi o propósito dessa sequência didática que trouxe a abordagem STEAM para a sala de aula de língua inglesa com o intuito de oportunizar momentos de vivências de dificuldades e de criatividade na solução de problemas. Dessa forma, pudemos constatar como a ideia da transdisciplinaridade, mais especificamente as concepções STEAM (Science, Technology, Engineering, Arts and Maths) e design thinking, contribuiu significativamente para que os alunos, além de enriquecer seus repertórios linguísticos, se sentissem estimulados a participar e a propor soluções para a problematização estabelecida e também para que pudessem aprender mais sobre arte.

A divisão das aulas em três etapas foi realizada considerando a imersão total dos alunos na arte renascentista, para que conhecessem suas características e filosofias, bem como os principais artistas do movimento e, além disso, para que pudessem entender qual era o contexto em que viviam os artistas daquela época. Depois de explicar como analisar uma obra de arte, os alunos foram encorajados a explicar o que sentiam diante de cada obra, utilizando o repertório linguístico ensinado e aprendido nas aulas.

No terceiro momento, durante o desenho realizado pelos alunos na postura horizontal embaixo das carteiras, puderam perceber todas as dificuldades sofridas pelos artistas do renascimento ao realizarem suas obras. Houve um levantamento da problemática enfrentada por Michelangelo ao pintar o teto da Capela Sistina e, após essa conscientização, os alunos foram instigados a apresentarem soluções utilizando a abordagem do design thinking de forma simplificada para resolver, ou pelo menos amenizar, o problema de Michelangelo. Surgiram várias sugestões, entretanto, as que mais se destacaram foram os moldes que diminuiriam o tempo gasto por Michelangelo para pintar o teto e a utilização de um material (ainda a ser pesquisado) em que a pintura pudesse ser realizada e posteriormente transferida em etapas para o teto. Ao final das aulas, pudemos perceber que os alunos enriqueceram seus conhecimentos não só 
específicos da disciplina de Língua Inglesa, mas de diversas outras áreas como História, Arte, Design e Geografia.

\section{Referências}

BACIC, L; MORAN, J. Metodologias Ativas para uma Educação Inovadora: uma Abordagem Teórico-Prática. $1^{\text {a }}$ ed. Porto Alegre: Penso, 2018.

CROSS, N. Design thinking: understanding how. Oxford, UK: Berg, 2011.

DAM, Rikke; SIANG, Teo. What is Design Thinking and Why Is It So Popular?. 2018. Disponível em: https://www.interaction-design.org/literature/article/what-is-designthinking-and-why-is-it-so-popular. Acesso em: 17 out. 2018.

DANAH, H. Creating STEAM with Design Thinking: beyond STEM and Arts Integration. The STEAM Journal. n. 3, p. 1-11, 2017

FABRÍCIO, B. F. Linguística aplicada como espaço de "desaprendizagem”: redescrições em curso. In: MOITA LOPES, L. P. (org.) Por uma linguística aplicada INdisciplinar. São Paulo: Parábola, 2006. p. 45-65.

FERRAL, V. E. Jr. Liberal Arts at the brink. EUA: Harvard University Press, 2011.

FISCHER, A; SCRIVEN, M. Critical Thinking: its definition and assessment. CA/EUA: Edgepress, 1997.

GARCÍA, O. Bilingual Education in the $21^{\text {st }}$ Century: a global perspective. Malden, MA: Wiley-Blackwell, 2009.

GOLDMAN, S; KABAYADONDO, Z. Taking design thinking to school: how the technology of design can transform teachers, learners and classrooms. $1^{\mathrm{a}}$ ed. Routledge: New York, 2017.

GUN, J. The evolution for STEM and STEAM in the US. 2017. Disponível em: https://education.cu-portland.edu/blog/classroom-resources/evolution-of-stem-andsteam-in-the-united-states/. Acesso em: 20 out. 2018.

MELLO, H. A. B. Educação bilíngue: uma breve discussão. Horizontes de Linguística Aplicada, v. 9, n. 1, p. 118-140, 2010.

MICHAEL J. SPECTOR. An editorial on research and development in and with educational technology. Educational Technology, v. 55, nº 2, p. 19-25, 2015.

MOITA LOPES, L. P. Uma linguística aplicada mestiça e ideológica: interrogando o campo como linguista aplicado. In: MOITA LOPES, L. P. (org.) Por uma linguística aplicada INdisciplinar. São Paulo: Parábola, 2006. p. 13-44. 
PORTNOI, L; BAGLEY, S; RUST, V. D. Higher Education, Policy and the Global Competition Phenomenon. New York: Palgrave Macmillan, 2010.

SPECTOR, M. J., XUNG, IFHENTALER, D; Emerging Technologies for STEAM Education: Full STEAM ahead. Suíça: Springer International Publishing Switzerland, 2015.

Vídeos utilizados nas aulas:

Brunner, Kirsten. Vídeo. (6 min). Michelangelo and The Sistine Chapel. Publicado pelo canal Kirsten Brunner, 2016. Disponível em: https://www.youtube.com/watch? $v=a b W 2 k Z 5$ Eww\&t=6s. Acesso em: 03 set 2020.

Zucker, Steven. Vídeo. (6 min). The ceiling of the Sistine Chapel: Publicado pelo canal Khan Academy. 2013. Disponível em: https://www.youtube.com/watch?v=PEE3B8Fsuc0. Acesso em: 03 set 2020.

Recebido em: 16 maio 2020.

Aceito em: 17 jun. 2020. 